\title{
Metallographic Studies of Dissimilar AI-Cu Laser-Welded Joints Using Various Etchants
}

\author{
Pascal Schmalen $^{1} \cdot$ Karthik Mathivanan ${ }^{1} \cdot$ Peter Plapper $^{1}$
}

Received: 11 June 2018 / Revised: 5 October 2018 / Accepted: 6 November 2018 / Published online: 15 November 2018

○ Springer Science+Business Media, LLC, part of Springer Nature and ASM International 2018

\begin{abstract}
The welding of $\mathrm{Al}$ and $\mathrm{Cu}$ is considered as difficult due to the formation of intermetallic compounds, which cause a brittle joint with increased electrical resistance. This paper investigates etching techniques that were used to contrast the intermetallic compounds for optical microscope analysis. A $0.5 \mathrm{~mm}$ AA- 1050 sheet was welded to a $0.5 \mathrm{~mm}$ SF-Cu sheet in overlap configuration. The cross sections were etched by using 17 different reagents, including common Al-grade 2xxx etchants, Al-bronze etchants, and specific IMC etchants. A complete microstructural characterization, including the formation of intermetallic compounds, is presented. The experimental result showed that a clear distinction of metallurgic structures is possible, thus enabling a more detailed analysis of $\mathrm{Al}-\mathrm{Cu}$ welds. It was found that etchants \#09, \#14, and \#16 revealed best the four different intermetallic compounds $\theta-\mathrm{Al}_{2} \mathrm{Cu}, \eta-\mathrm{AlCu}, \zeta-\mathrm{Al}_{3} \mathrm{Cu}_{4}$, and $\gamma-\mathrm{Al}_{4} \mathrm{Cu}_{9}$.
\end{abstract}

Keywords Laser welding $\cdot$ Etching routines $\cdot$ Optical microscopy $\cdot$ Aluminum $\cdot$ Copper $\cdot$ Intermetallic compounds

\section{Introduction}

The joining of dissimilar $\mathrm{Al}$ and $\mathrm{Cu}$ is a promising technology for Li-ion batteries electrodes due to the contactless power delivery and low-inertia positioning system. In a comparative study, it was found that the mechanical strength and electrical conductivity are highest for laser-welded battery cells compared to resistance and ultrasonic welding [1]. The laser joining of dissimilar material is performed by selectively melting only one of the joining partners, thus controlling the intermixture. Based on diffusion and convection, a dissimilar alloy is formed. It consists, depending on the solubility the alloys, of a solid solution and intermetallic compounds (IMCs). The formation of IMC is depending on the atomic size, crystal structure, electronegativity, and valency of both metals; the more they differ, the more likely the formation of IMCs [2]. IMCs are usually avoided, because they degrade the performance of the joint relative to the parent material; for example, they shift the wanted metallic properties of the base materials, good conductivity and ductile break behavior, into higher resistivity and a brittle

Pascal Schmalen

pascal.schmalen@uni.lu

1 Universität Luxemburg, rue Richard-Coudenhouve Kalergii, 1351 Esch-sur-Alzette, Luxembourg break behavior. In order to increase the understanding of the IMC formation in the joint, a detailed metallurgical analysis of the weld seam is needed.

Regarding the dissimilar $\mathrm{Al}-\mathrm{Cu}$ joint, it consists of pure $\mathrm{Al}$ as one base material and pure $\mathrm{Cu}$ as the other one. The weld seam will consist of solid solutions of both material and several IMCs, as the binary phase diagram indicates; see Fig. 1 [3]. Even more, metastable phases, for example the $\beta^{\prime}$-phase at $77 \%$ at. $\mathrm{Cu}$, could be found [4]. In fact, while joining $\mathrm{Al}$ and $\mathrm{Cu}$, the chemical composition of the joint passes through the entire phase diagram, and depending on the intermixture and cooling rate, this pass is a few microns or less thick. The properties of the varying IMC are not similar, some of them were found to be harder and with higher resistivity [5], and others are more crack sensitive [6].

Weld seam characteristics, such as welding depth and seam width, were measured by performing metallographic cross sections. In order to analyze the intermixture, and therefore the formation of IMC in the weld seam, cross sections were used. Further investigations such as SEM and hardness measurement use polished cross sections as well. In order to contrast and analyze the specific structure of a weld seam, etchants are used to reveal weld seam details, such as IMC, grain structure, and heat-affected zone $[7,8]$. The results were found on frictions stir welded $\mathrm{Al}-\mathrm{Cu}$ joints, and the mechanical properties of the joint are depending on the 

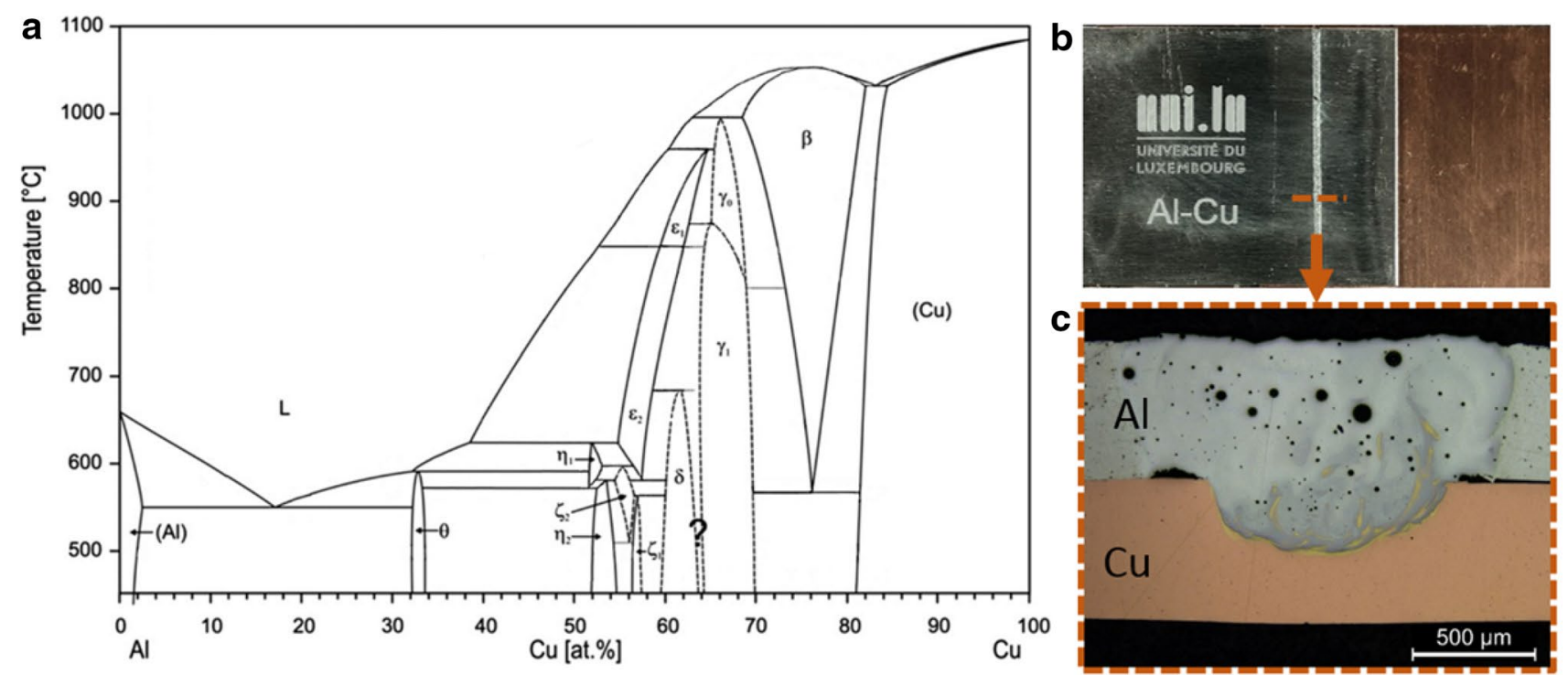

Fig. 1 (a) Binary phase diagram, as investigated by [26]. (b) Al-Cu joint sample, laser welded. (c) Cross section of Al-Cu weld seam, unetched

intermixture and thus the formation of IMC. The authors in $[9,10]$ use XRD, SEM, EDS, and optical microscope (OM) methods to describe the weld seam; however, limited information on sample preparation (which is key to obtaining high-quality data) was provided, and no information about etching methods.

Laser-welded $\mathrm{Al}-\mathrm{Cu}$ joint was characterized by [11]; using SEM techniques, four characteristic layers were identified. Each layer consists of varying IMC and base material, and the author stated that joint properties can be linked to their relative layer. In [6], five layers were identified using an SEM, too. The authors prepared optical micrographs, etched with Keller's reagent. The structure found by optical microscopy was not included in the manuscript. The authors in [12] described an Al-Cu interlayer using SEM, without using optical micrographs.

Only little information on the preparation of dissimilar $\mathrm{Al}-\mathrm{Cu}$ cross sections for optical microscopy can be found in the literature. Information about the used etchants were limited to a minimum or not mentioned. Optical micrographs have several advantages over electron microscopy. Chromatic images increase the contrast of metallurgical structures, which can be further enhanced by using selective etchants. Furthermore, the use of optical microscopy is more cost and time efficient than SEM.

In this paper, metallurgical cross sections of laser-welded $\mathrm{Al}-\mathrm{Cu}$ were analyzed using light optical microscope. The main objective of the paper is to present the etching of $\mathrm{Al}-\mathrm{Cu}$ weld seams to observe different patterns, features that are formed in the weld seams. A review of 17 etchants for $\mathrm{Al}-\mathrm{Cu}$ welds is presented and summarized. The reliable identification of structures in the Al-Cu weld seam is the starting point for further investigation on the formation of the IMC in the weld seam and how the IMCs affect the properties of the joint.

\section{Materials and Experimental setup}

All tests were carried out using AA-1050 in soft (annealed) state, welded to SF-Cu in soft state. The materials were welded without any surface cleaning routine; attention was paid on welding an uncrumpled and flat surface in order to avoid weld irregularities. The welded coupons had a size of $40 \times 40(\mathrm{Al})$ and $40 \times 45(\mathrm{Cu})$ and were prepared from $40 \mathrm{~mm}$ rolled band material with a thickness of $0.5 \mathrm{~mm}$. The materials were welded in overlap configuration, with $\mathrm{Al}$ on top. The weld seam was $40 \mathrm{~mm}$ width across both materials.

The welds were performed using a TruDisk 2000 with $1030 \mathrm{~nm}$ wavelength and an energy density of $32 \mathrm{MW} / \mathrm{cm}^{2}$. No shielding gas was used, since it was found that the lack of shielding gas does not alter the mechanical properties of the joint [13]. The weld seam width is $0.81 \mathrm{~mm}$, achieved by wobbling, laser power was set to continuous $700 \mathrm{~W}$, and a feed rate is $290 \mathrm{~mm} / \mathrm{s}$. The weld seams were welded with high laser power in order to achieve high intermixture. The higher the intermixture, the more IMCs are formed which then are more accessible to analyze. It is known that a high energy input increases the brittleness and thus creates more cracks; furthermore, the weld becomes more porous. Since we want to analyze the contrast capability of different etchants, the mechanical properties and joint quality are not of interest for this study. 
The cross sections have been prepared using 320 and 800 grinding paper, 6,3 , and $1 \mu$ diamond polishing, and $0.25 \mu \mathrm{m}$ diamond end polishing, as reported in Table 1 . The samples were sectioned using a puncher, and each sample contained five weld seams. The samples were positioned into silicon molds, fixed with plastic clips, and cold embedded using a quick hardening, acryl-based resin. The samples then were grinded/polished using a semiautomated grinding machine.

The weld seams were etched using multiple etching agents, see Table 2, in order to identify the IMC and analyzed by optical microscope. The chemical composition, etching time, and temperature are reported in Table 2. The etchants were chosen based on common literature on $\mathrm{Al}-\mathrm{Cu}$ dissimilar welds. Technical Al-Cu alloys are mostly limited to chemical ranges within the solubility of the metals to each other, which is about $18 \%$ at. $\mathrm{Al}$ to $\mathrm{Cu}$ and approx. $2 \%$ at. $\mathrm{Cu}$ to $\mathrm{Al}$ [4]. Thus, several etchants are based on either aluminum bronze or copper-alloyed aluminum, known as 2.xxx alloys. Chromium(IV) oxide-based etchants were found in various publications, for example [14-17], and used as copper etchants. Recent studies have shown that those chemicals were carcinogenic and mutagenic. For these reasons, the chemicals and their applications will be restricted by the end of 2017 [18]. As a result, those etchants will not be used in the current investigations.

\section{Results}

The etchants shown in Table 1 were applied to the $\mathrm{Al}-\mathrm{Cu}$ weld seam to reveal the weld seam structure, heat-affected zone (HAZ), and base material grains. The detected structures are presented in Fig. 2 and described in Table 3 in a schematic cross section. It was found that nine distinct regions can be identified inside the weld seam. They were numbered from 1 to 9 , starting from the $\mathrm{Al}$ side.

The main structure exists in every weld seam, but not an individual etchant could reveal all the mentioned structures; each etchant contrasted a specific structure, also depending on etching procedure. Considering the finite resolution of optical microscopy, it was difficult to observe some structures, especially 5-6-7. Therefore, the main structures which can be found in most cross sections are 1-2-3-4-8-9. The intermixture is high for laser-welded joints; thus an alternating, but ordered sequence or structures 1-9 are likely to be obtained. The patterns and microstructures resulting in the weld seam are classified into nine different structures or regions.

It was found that structure 4 is the $\mathrm{Al}_{2} \mathrm{Cu}-\theta$ phase, structure 5 the $\mathrm{AlCu}-\eta$ phase, and structure 7 the $\mathrm{Al}_{4} \mathrm{Cu}_{9}-\gamma$ phase. Structure 6 consists of $\zeta$-phase $\left(\mathrm{Al}_{3} \mathrm{Cu}_{4}\right)$. The identification of the phases was based on micro-XRD results and is presented in [26]. A similar description of the structures in the weld seam was discussed by [10]. Four distinct zones, phases, as found in the literature were identified. The columnar dendrites, region (4), resemble zone 2 (Lump $\left(\Theta-\mathrm{CuAl}_{2}\right)+$ eutectic $\left.(\alpha+\Theta)\right)$. The region (3) is corresponding to the zone 3 (eutectic $\alpha+\theta$ ) and the region (2) to zone 4 (Dendrites $\alpha+\mathrm{Al}$ ). Zone 1 was identified by the as $\gamma_{2}$ $\mathrm{Cu}_{9} \mathrm{Al}_{4}$ grains.

Some structures can be identified before etching; see Fig. 3a. For example, dendrites (4)+(5), or the copper bronze (8), are colored in yellow. Application of etching routine to the weld seam resulted in an increased contrast of the varying $\mathrm{Al}-\mathrm{Cu}$ intermetallic structures formed during welding of aluminum and copper. Figures 3 and 4 show the specific results, which are described hereafter.

\#01: Keller The Keller etching is commonly used for $\mathrm{Al}-\mathrm{Cu}$ weld seams. Etching for 5-15 s revealed the structure (4, which is clearly contrasted from (3; see Fig. 3c. Increasing the etching time to $2 \mathrm{~min}$ strongly etched the regions (2) and (3), and (4) was etched too. By this, (5) is more contrasted. The results are best for short etching times; see Fig. 3c.

\#02: Weck This KE_002 etched both base materials Al1 and $\mathrm{Cu}$ (9. However, grain structures were not revealed. The area (2) appeared blue, even at higher magnification of $200 \times$. The developed color was not uniform. The etchant was dissolving the cotton and attacking the nitrile gloves.

Table 1 Description of grinding and polishing procedure used

\begin{tabular}{|c|c|c|c|c|c|}
\hline Step & Description of the procedure (cloth type/size) & Time, min & Speed & Force, $\mathrm{N}$ & Lubricant \\
\hline \multirow[t]{2}{*}{ Grinding } & SiC paper 320 grit & 2 & $250 \mathrm{RPM}$ & $20-25$ & Water based \\
\hline & $\mathrm{SiC}$ paper 800 grit & 4 & & & \\
\hline Cleaning & Clean with ethanol in ultrasonic bath & 2 & & & \\
\hline \multirow[t]{4}{*}{ Polishing } & Hard, woven cloth with $6 \mu \mathrm{m}$ diamond suspension & 3 & $150 \mathrm{RPM}$ & $20-25$ & Water based \\
\hline & Short-napped velvet cloth with $3 \mu \mathrm{m}$ diamond suspension & 2 & & & \\
\hline & Soft, long-napped cloth with $1 \mu \mathrm{m}$ diamond suspension & 2 & & & \\
\hline & Soft, long-napped cloth with $0.25 \mu \mathrm{m}$ diamond suspension & 1 & & & \\
\hline Cleaning & Clean with ethanol in a ultrasonic bath & 2 & & & \\
\hline
\end{tabular}


Table 2 List of 17 etchants, which were used during the investigations

\begin{tabular}{|c|c|c|c|c|c|c|}
\hline $\mathrm{Nr}$ & Name & Chemical composition & Etching time, $\mathrm{s}$ & Temp., ${ }^{\circ} \mathrm{C}$ & Etching method & Literature \\
\hline$\# 01$ & Keller & $\begin{array}{l}950 \mathrm{ml} \mathrm{H}_{2} \mathrm{O} ; 25 \mathrm{ml} \mathrm{HNO}_{3} \\
15 \mathrm{ml} \mathrm{HCl} ; 10 \mathrm{ml} \mathrm{HF}\end{array}$ & Up to $1 \mathrm{~min}$ & RT & Wipe/swabbed by cotton & {$[7,8,16,19-21]$} \\
\hline$\# 02$ & Weck & $\begin{array}{l}100 \mathrm{ml} \mathrm{H}_{2} \mathrm{O} ; 4 \mathrm{~g} \mathrm{KMnO}_{4} ; 1 \mathrm{~g} \\
\quad \mathrm{NaOH}\end{array}$ & $\mathrm{Up}$ to $60 \mathrm{~s}$ & RT & Immersion & [19] \\
\hline \#03 & Two-step etching with Weck & $\begin{array}{l}\text { Pre-etchant: } 1 \mathrm{~g} \mathrm{NaCl} ; 50 \mathrm{ml} \\
\mathrm{H}_{3} \mathrm{PO}_{4} \\
\text { Second step: \#02 Weck's }\end{array}$ & Up to $3 \mathrm{~min}$ & $70^{\circ} \mathrm{C}$ & Immersion & [22] \\
\hline$\# 04$ & Macro-etchant $(\mathrm{Cu})$ & $\begin{array}{l}15 \% \text { Ammonium persulfate; } \\
85 \% \mathrm{H}_{2} \mathrm{O}\end{array}$ & $15-60 \mathrm{~s}$ & RT & Cotton/immersion & {$[16,23]$} \\
\hline$\# 05$ & Tucker's reagent & $\begin{array}{l}5 \mathrm{ml} \mathrm{HF} ; 20 \mathrm{ml} \mathrm{HNO}_{3} ; 20 \mathrm{ml} \\
\mathrm{HCl} ; 60 \mathrm{ml} \mathrm{H}_{2} \mathrm{O}\end{array}$ & $15-60 \mathrm{~s}$ & RT & Immersion & {$[15,16]$} \\
\hline \#06 & Al etchant & $80 \mathrm{ml} \mathrm{H}_{2} \mathrm{O} ; 20 \mathrm{ml} \mathrm{H}_{2} \mathrm{SO}_{4}$ & $30 \mathrm{~s}-3 \mathrm{~min}$ & $70^{\circ} \mathrm{C}$ & Immersion & [14] \\
\hline \#07 & Macro-Al & $100 \mathrm{ml} \mathrm{H}_{2} \mathrm{O}, 15 \mathrm{~g} \mathrm{NaOH}$ & $3-5 \mathrm{~min}$ & $\mathrm{RT} / 70^{\circ} \mathrm{C}$ & Immersion & {$[16,20]$} \\
\hline$\# 08$ & Klemm's III reagent $(\mathrm{Cu})$ & $\begin{array}{l}5 \mathrm{ml} \text { Sat. aqueous sodium } \\
\text { thiosulfate } \\
45 \mathrm{ml} \mathrm{H}_{2} \mathrm{O} ; 20 \mathrm{~g} \text { potassium } \\
\text { bisulfite, use fresh }\end{array}$ & Up to $3 \mathrm{~min}$ & RT & Immersion & {$[16,24]$} \\
\hline$\# 09$ & $\begin{array}{l}\text { Herenguel \& segond (Al etch- } \\
\text { ant) }\end{array}$ & $\begin{array}{l}25 \mathrm{ml} \mathrm{H}_{2} \mathrm{SO}_{4} ; 70 \mathrm{ml} \mathrm{H}_{3} \mathrm{PO}_{4} ; \\
\quad 5 \mathrm{ml} \mathrm{HNO}_{3}\end{array}$ & $30 \mathrm{~s}-2 \mathrm{~min}$ & $85^{\circ} \mathrm{C}$ & Immersion & {$[15,17]$} \\
\hline$\# 10$ & Kroll (Al-Cu alloys) & $\begin{array}{l}92 \mathrm{ml} \mathrm{H}_{2} \mathrm{O} ; 6 \mathrm{ml} \mathrm{HNO}_{3} ; 2 \mathrm{ml} \\
\mathrm{HF}\end{array}$ & $15 \mathrm{~s}-1 \mathrm{~min}$ & RT & Immersion & {$[16,20,21]$} \\
\hline$\# 11$ & $\Theta-\mathrm{Al}_{2} \mathrm{Cu}$ etchant (red) & $\begin{array}{l}1 \mathrm{~g} \text { Ammonium molybdate } \\
6 \mathrm{~g} \text { Ammonium chloride } \\
200 \mathrm{ml} \mathrm{H}_{2} \mathrm{O}\end{array}$ & $30 \mathrm{~s}-2 \mathrm{~min}$ & RT & Immersion & [19] \\
\hline$\# 12$ & $\mathrm{Cu}$ etchant & 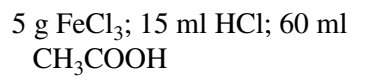 & $15 \mathrm{~s}-1.30 \mathrm{~min}$ & RT & Immersion & {$[8,14-16,23]$} \\
\hline$\# 13$ & $\mathrm{Cu}$ etchant & $\begin{array}{l}120 \mathrm{ml} \mathrm{H}_{2} \mathrm{O} ; 10 \mathrm{~g} \mathrm{Cu} \text {-ammo- } \\
\text { nium chloride } \\
\text { Add ammonia till deposit gets } \\
\text { formed }\end{array}$ & $\begin{array}{l}20 \mathrm{~s}-1 \mathrm{~min} \\
\text { From } 2 \mathrm{~s}\end{array}$ & RT & Immersion & [14] \\
\hline$\# 14$ & $\Theta-\mathrm{Al}_{2} \mathrm{Cu}$ etchant (blue) & $\begin{array}{l}1 \mathrm{~g} \text { Ammonium molybdate } \\
6 \mathrm{ml} \mathrm{HNO} 3,16 \mathrm{ml} \mathrm{H}_{2} \mathrm{O} \\
60 \mathrm{ml} \mathrm{CH} \mathrm{CHOH}_{3} \mathrm{COOH}\end{array}$ & $15 \mathrm{~s}-2 \mathrm{~min}$ & RT & Cotton/immersion & [19] \\
\hline \#15 & ASTM 30 & $\mathrm{H}_{2} \mathrm{O}_{2} ; \mathrm{H}_{2} \mathrm{O} ; \mathrm{NH}_{4}$ in $1: 1: 1$ & $5 \mathrm{~s}-1 \mathrm{~min}$ & RT & Immersion & {$[14-16,21,23]$} \\
\hline \#16 & ANPE $80 / 5 / 5 / 10$ & $\begin{array}{l}\mathrm{H}_{3} \mathrm{PO}_{4}(73 \%) ; \mathrm{HNO}_{3}(3.1 \%) \\
\mathrm{CH}_{3} \mathrm{COOH}(3.3 \%) ; \mathrm{H}_{2} \mathrm{O} \\
\quad(20.6 \%)\end{array}$ & $30 \mathrm{~s}-2 \mathrm{~min}$ & RT & Cotton/immersion & {$[17,25]$} \\
\hline \#17 & Barker & $1.8 \%$ fluoboric acid in water & Up to $2 \mathrm{~min}$ & - & Electrolytic, $20-45 \mathrm{~V}$ & {$[16,19,20]$} \\
\hline
\end{tabular}

\#03: 2-step etchant In this two-step etching, Al-Cu weld seam is first etched with KE_03 and then it is etched with KE_02 (Weck). The dendritic region (4) appeared brown/dark with a light contrast of (4) from (3). (4) and (5) were colored in light blue; the etching was not uniform.

\#04: Macro-Cu Starting from base Al1, the regions (2)to (4) were not etched. At reduced magnification $50 \times$, the region(4) was not seen, but (5) appeared in blue. In (7), an acicular, martensitic-like structure is revealed. The copper (9) was etched and the grains are well contrasted.

\#05: Tucker KE_05 manly etched (2) and slightly etched (3), giving a contrast between (2) to (4). The etchant attacked the transition between (5) and (6, revealing cavities of a few microns diameter. In (4), the dendrites were striped with a lamellar appearance with gray and black in color.

\#06: Al etchant This etchant, which was applied at $70^{\circ} \mathrm{C}$, mainly etched the dendrites (4). The structures in (2) and (3) were not clearly seen. A light contrast was found between (4) and (5). This etchant is revealing only the dendritic structure (5). The copper-rich zones (6-(9) were not etched.

\#07:Macro-Al This etchant revealed the grains of Aluminum (1). The regions (2) and (3) were etched, the contrast was best for etching times of $3 \mathrm{~min}$. A good contrast between regions 


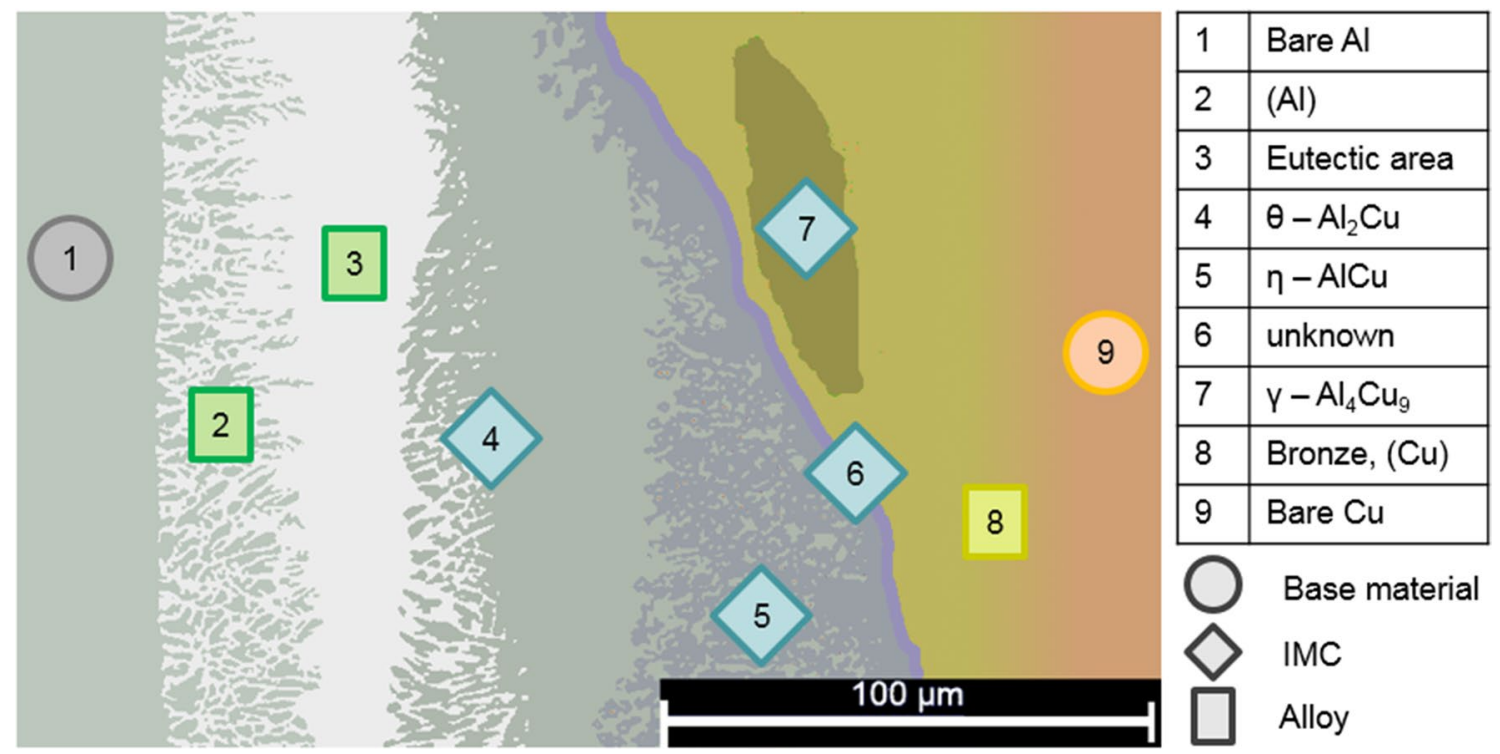

Fig. 2 Schematic cross section of the Al-Cu weld seam with main metallurgic structures 1-9, colors similar to unetched weld seams (structure 3 is gray too and gives a bad contrast to 2 and 4). Structures 4-7 are Al-Cu intermetallic compounds

Table 3 Description of revealed structures, Fig. 2

\begin{tabular}{|c|c|}
\hline Structure & Description \\
\hline (1) & Structure (1) is the aluminum base material \\
\hline (2) & Coming from $\mathrm{Al}$, a dissolution of aluminum in weld seam is defined as (2) \\
\hline (3) & The region (3) is a transition area which includes the eutectic point of $(\mathrm{al})+\theta$ \\
\hline (4) & $\begin{array}{l}\text { The first dendritic structure is defined as }\left(4 \text {, according to the phase diagram, see Fig. } 1 \text {, this is the theta phase } \mathrm{Al}_{2} \mathrm{Cu} \text {, also found by }\right. \\
\text { [10]. The structure } 4 \text { represents a columnar dendritic structure, which is found in the every weld seam. These look like peaks with } \\
\text { pointed tower-like shape; see Fig. } 3 \text {. The peaks range from } 3 \text { to } 70 \mu \mathrm{m} \text {, rarely even longer }\end{array}$ \\
\hline (5) & $\begin{array}{l}\text { The next dendritic structure is defined as (5.The dendrites are only a few microns long, rounded, and fine distributed. According to } \\
\text { the phase diagram, this phase is the eta phase, } \mathrm{AlCu} \text {, which agrees with SEM measurements }\end{array}$ \\
\hline (6) & Region( is a transition zone, which is found between (5) and ( 8 , revealed by few etchants at high magnification \\
\hline (7) & $\begin{array}{l}\text { Structure (7) is a copper-rich zone with needle-like microstructure found between } 6 \text { and the Al bronze } 8 \text {. According to [4], a marten- } \\
\text { sitic structure is likely, based on metastable transformation of the } \beta \text {-phase. The needles are about } 5 \mu \mathrm{m} \text { in length and only visible at } \\
\text { high magnification; see Fig. 3a }\end{array}$ \\
\hline (8) & $\begin{array}{l}\text { Structure (8) is Al-bronze, well distinguishable by color, with a gradient to orange (pure copper (9). Copper can dissolve up to } 18 \% \text { at. } \\
\text { Al forms a solid solution; thus, no metallurgic structures can be found. Non-etched cross sections show a uniform yellow region; } \\
\text { after etching, a new metallurgic structure } 7 \text { between the copper bronze and } 6 \text { was distinguished and well contrasted. This structure } \\
\text { is the phase } \gamma-\mathrm{Al}_{4} \mathrm{Cu}_{9}\end{array}$ \\
\hline (9) & The last structure was identified as the copper base material. Also included in this region is the heat-affected zone in the copper side \\
\hline
\end{tabular}

(4) and (5) was found, whereby the region (4) was gray/brown and the dendritic structure (5) appeared bright white.

\#08: Klemm3 (Cu) The transition region (6) was colored in black, and the subsequent regions (8) and (9) were seen colored in orange and yellow, respectively. (7) was etched, revealing a brown/gray, martensitic-like structure, which is $\gamma-\mathrm{Al}_{4} \mathrm{Cu}_{9}$; see Fig. 4d. In the region (9, base copper grains were revealed with a good contrast.
\#09: Herenguel \& segond KE_09 is a viscous etchant, which dissolves the cotton. The region (4) was colored in brown and (5) appeared in gray. The etchant attacked the area between (5) and (6, giving a good contrast of (5) to (6. A clear contrast of regions (7) and (8) was observed near the Al-Cu interface; see Fig. 4c. In the region (9, copper grains were revealed by this etchant. 

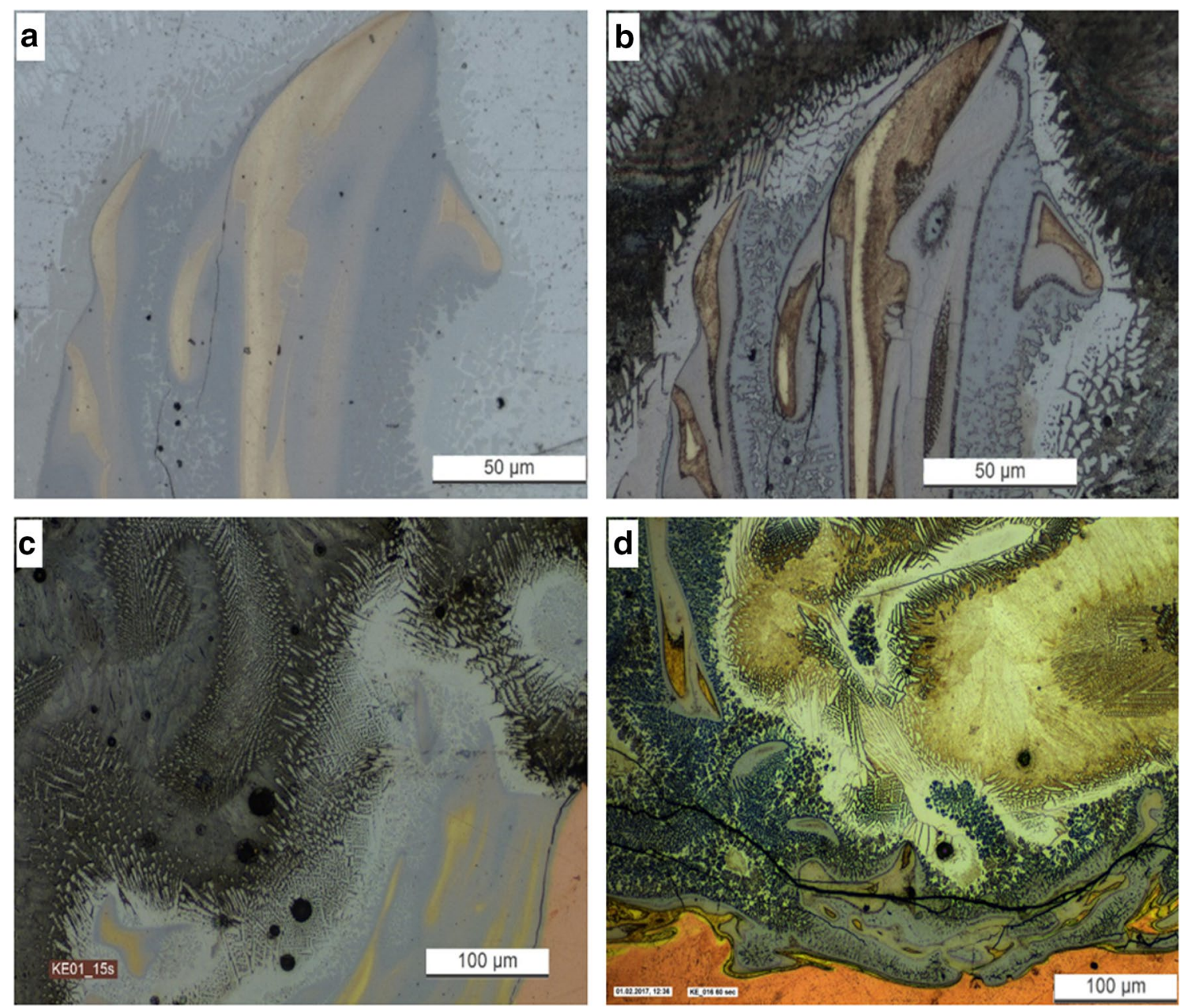

Fig. 3 (a) Unetched micrograph, several structures can be detected. (b) The same micrograph as in (a), but etched with \#14. The IMCs are now contrasted. The $\gamma$-phase, region 7 , which was hidden in

region (8), is now clearly visible. (c) The Keller etchant, \#01, giving contrast in regions (2)-4. (d) The etchant \#16 gives more contrast than the commonly used Keller, \#01

\#10: Kroll This etchant mainly etched (3, increasing the etching time up to $1 \mathrm{~min}$, (4) was etched too. Structure (4) was contrasted with (3)+(5), and it has a dark gray color, whereby (3) was in brown/black.

\#11 This solution etched the base material (9) producing a pink and orange color region but it did not reveal the grains of copper. At higher magnification, (4) was etched light blue/ pink, (5) appeared in purple, (3) was colored in yellow and (2) blue. The other regions (6)-8 were all colored too, but no contrast was seen making it difficult to separate from one another. Overall, the received color depended strongly on the etching time and on the deposition of the etchant to the specimen, thus preventing a clear structure identification.

\#12: FeCl3 This chemical solution etched the base Al (1), causing many black spots of a few microns diameter. The base material (9) was etched too, but the grain structure was

not well contrasted. The regions (2) and (3) were hard to identify as they were strongly etched within $15 \mathrm{~s}$. Because of no clear contrast, it was difficult to see (4) and (5). The dendrites (4) had a ginger color, possibly deriving from the dissolved copper. An increase in etching time to $1 \mathrm{~min}$ was enhanced to contrast of (4) but did not show (5); the base materials (1) and (9) were over-etched.

\#13 KE_13 is a strong copper etchant, and the base material (9) was etched in less than $5 \mathrm{~s}$ and remained black. The structures (2) to (8) in the weld seam could not be identified.

\#14: $\vartheta$-tint etchant The etchant reveals a detailed structure coming from the base $\mathrm{Al}$ (2) to the columnar dendritic structure (4. An increased etching time resulted in strongly etched regions (4) $+(5$, with clear contrast to (3). By reducing the magnification to $20 \times-50 \times$ combined with reduced etching time, the dendrites 4 appear in a bright blue, see figure 

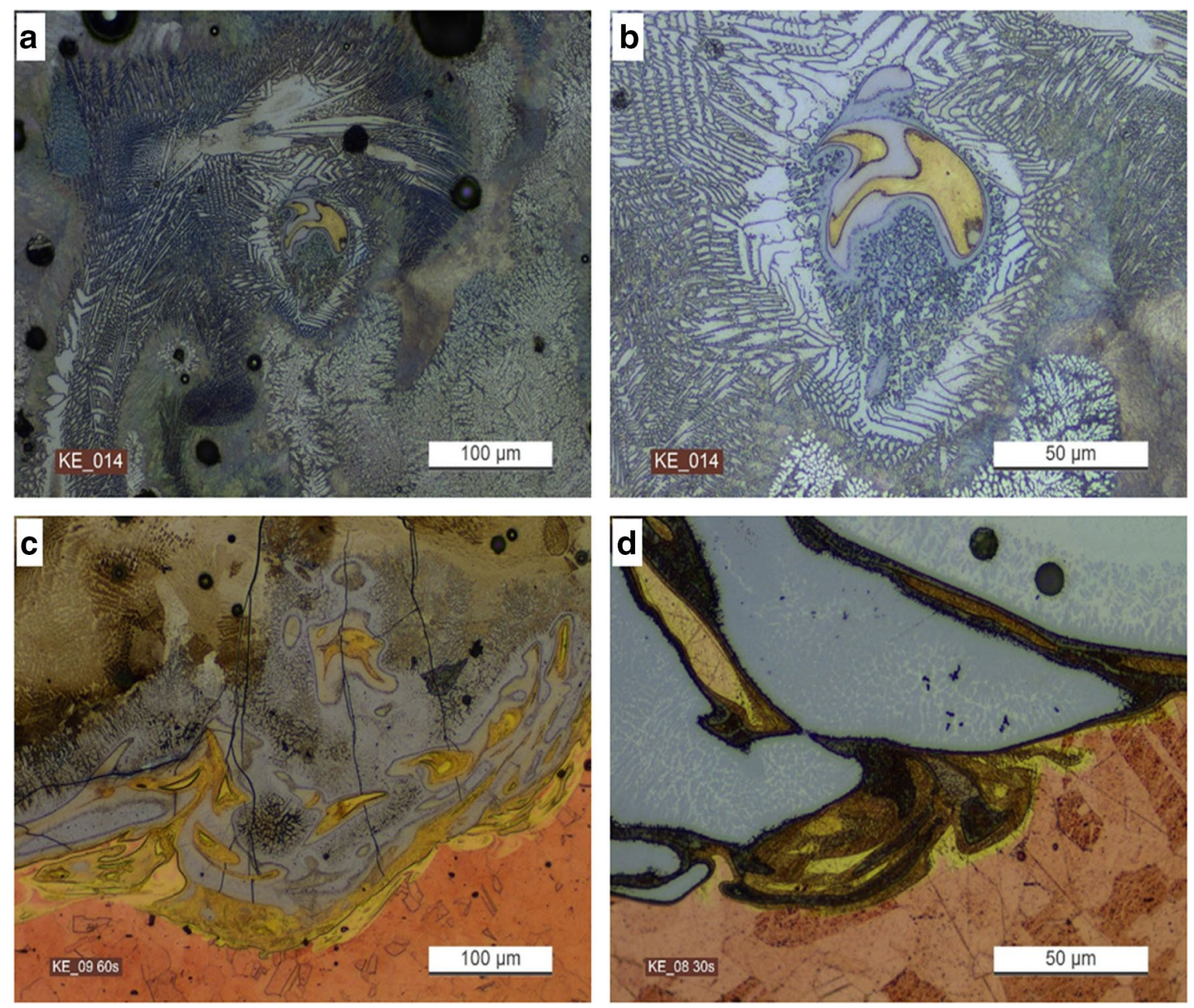

Fig. 4 (a) \#14 etchant colored the $\mathrm{Al}_{2} \mathrm{Cu}-\theta$-phase blue at $\times 20$ magnification. (b) The same micrograph from (a), at higher magnification. The etchant gave an excellent contrast for all the IMC regions (4)-(7).

a, which was also seen by [19]. The contrast from (5) to (6) is best for reduced etching time, the transition zone (6) was clearly identified, and see Figs. $3 b$ and $4 b$.

\#15:ASTM 30 KE_15 is a copper etchant, revealing the grain structure of (9) after a short etching time of $15 \mathrm{~s}$. The weld seam was not etched in (1)-(6), and only (3) was lightly etched after $60 \mathrm{~s}$. At that time, the copper was strongly etched, remaining dark on the micrographs. The copper was not etched in an acceptable way, and the color and contrast were not uniform.

\#16: ANPE 80/5/5/10 The dendrites (4) were well contrasted with (3) and (5) for etching times of 1 min. Structure (5) was mainly etched and excellently contrasted, giving a clear view on cracks in this structure. The transition zone (6) was not etched, giving a light contrast to (5. The grain structure of (9) was revealed best for $60 \mathrm{~s}$; see Fig. 3d. By reducing the magnification, the dendrites $₫$ appeared in dark blue.

(c) \#09, a copper etchant, giving good contrast between the Al-bronze (8) and $\mathrm{Al}_{4} \mathrm{Cu}_{9}-\gamma$. (d) The \#08 etchant is a more specific etchant, by selectively etching regions (6) and (7) and revealing the $\mathrm{Cu}$ grains

\#17: Barker The barker's etchant was the only electrolytic etchant in the list. While etching the aluminum, and revealing the grain structure on the base material and the weld seam, the copper was dissolved, as well as the IMC. No weld seam structure could be identified after.

\section{Discussion}

It was found that out of 17 defined etchants, only nine are usable to enhance the contrast of the micrograph. Furthermore, each etchant had a specific etching range and contrast range. Figure 5 summarizes the performance of each etchant to characterize the $\mathrm{Al}-\mathrm{Cu}$ joints. The columns in the table represent the structures from (1) to (9, and each row represents the etchants from \#01 to \#17. The table indicates which specific regions were etched (indicated by color) and which regions were clearly contrasted (marked by a cross). 


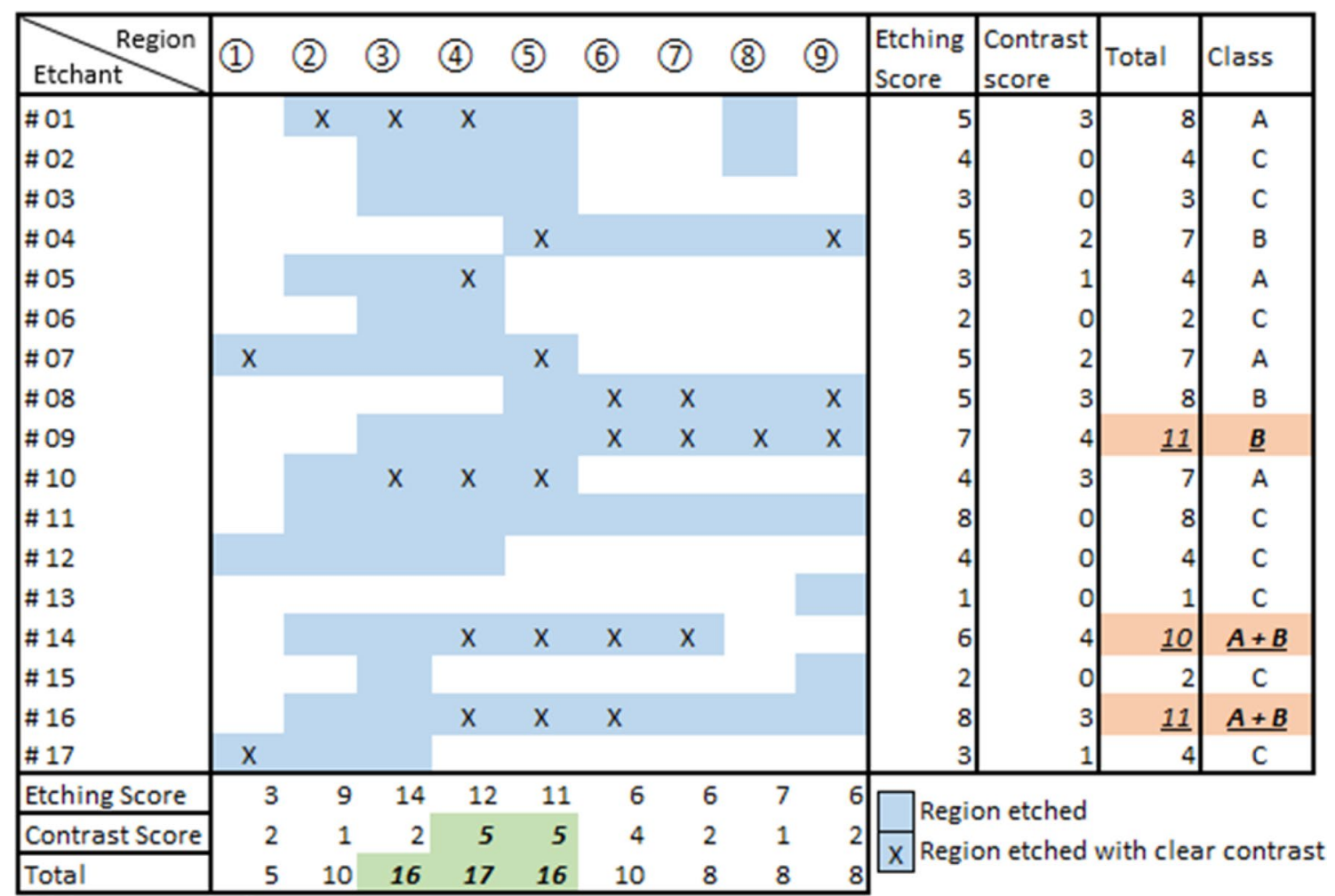

Fig. 5 Summary of the etchants and their etching capability per region. The blue color indicates an etching effect, and the cross indicates that the etchant significantly increased the contrast. The Al etchants and $\mathrm{Cu}$ etchant were well distinguishable. The most suitable etchants were found to be \#09, \#14, and \#16
In order to rate the etchants, scores were given based on the number of etched regions and the number of contrasted regions. The total score was calculated by summing up the etching score and contrast score. It was found that etchants $\# 09$, \#14, and \#16 performed best. The score was calculated for each region and each etchant.

The etchants were classified into Class A (Al etchants), $\mathrm{B}$ (copper etchants), $\mathrm{A}+\mathrm{B}$ (combined), and C (not recommended). Class A etchants etched the regions from (2) to (5) and provided a contrast of dendritic structure (4) or/and (5. Class $\mathrm{B}$ etchants were revealing the structures from (5) to 8 and a contrast of the structures (6, (7) or/and (9. Class $\mathrm{C}$ etchants show no contrast of the critical zone as shown in Fig. 4. The Class $\mathrm{A}+\mathrm{B}$ etchants etched the regions from (2) to 8 and contrasted the structures (5) and (6.

It was found that the structures (3), (4), (5) (Class A) were etched and contrasted by more etchants than the structures (6) and (7) (Class B). This was also observed in the literature, and the $\theta-\mathrm{Al}_{2} \mathrm{Cu}$ and $\eta$ - $\mathrm{AlCu}$ were more often described.

\section{Conclusions}

Aluminum (99.5\%) was welded to copper (99.9\%) using the laser braze welding principle. In order to analyze the weld seam by optical microscopy, a study on 17 etchants was carried out. Each etchant was analyzed and the developed color and the resulting contrast were reported. It was found that the etchants mainly etched the aluminum near weld seam (Class A etchants) or the copper near weld seam (Class B etchants). Eight etchants were classified as Class $\mathrm{C}$ and are not further recommended for analyzing $\mathrm{Al}-\mathrm{Cu}$ weld seams. The revealed weld seam structure was schematically shown in an exemplary cross section, which was subdivided into nine distinguishable structures which are parts of weld seams, base materials, or revealed intermetallic structures. The following conclusions were derived during these investigations: 
- The critical metallurgical structures in the Al-Cu weld seam can be effectively identified and contrasted by using an appropriate etchant.

- It was found that each etchant gives a specific contrast regarding the $\mathrm{Al}-\mathrm{Cu}$ weld seams, depending on which metallurgic structure should be analyzed; see the summarizing table, Fig. 5.

- The main structures identified in $\mathrm{Al}-\mathrm{Cu}$ weld seams were columnar dendritic $\theta-\mathrm{Al}_{2} \mathrm{Cu}$ and the finely distributed dendrites $\eta$-AlCu . Furthermore, the phases $\zeta\left(\mathrm{Al}_{3} \mathrm{Cu}_{4}\right)$ and $\gamma-\mathrm{Al}_{4} \mathrm{Cu}_{9}$ were revealed.

- Regarding laser braze-welded $\mathrm{Al}-\mathrm{Cu}$ weld seams, it was found that etchants \#09, \#14, and \#16 give the best contrast for further metallurgical analysis.

Acknowledgments This work is supported by the Fonds National de la Recherche (FNR) in Luxembourg under Grant No. AFR 10155468.

\section{References}

1. M. Brand, P. Schmidt, M. Zaeh, A. Jossen, Welding techniques for battery cells and resulting electrical contact resistances. J. Energy Storage 1(1), 7-14 (2015)

2. W.D. Callister, D.G. Rethwisch, Materials Science and Engineering (Wiley, New York, 2007)

3. N. Ponweiser, C.L. Lengauer, K.W. Richter, Re-investigation of phase equilibria in the system $\mathrm{Al}-\mathrm{Cu}$ and structural analysis of the high-temperature phase e1- $\mathrm{Al}(1-\mathrm{d}) \mathrm{Cu}$. Intermetallics 19(11), 1737-1746 (2011)

4. T.B. Massalski, The Al-Cu (Aluminum-Copper) system. Bull. Alloy Phase Diagr. 1(1), 27-33 (1980)

5. T. Solchenbach, P. Plapper, Mechanical characteristics of laser braze-welded aluminum-copper connections. Opt. Laser Technol. 54, 249-256 (2013)

6. Z. Xue, S. Hu, J. Shen, D. Zuo, J. Elijah Kannatey-Asibu, Microstructure characterization and mechanical properties of laserwelded copper and aluminum lap joint. J. Laser Appl. 26(1), 012002-1-012002-6 (2014)

7. J. Ouyang, E. Yarrapareddy, R. Kovacevic, Microstructural evolution in the friction stir welded 6061 aluminum alloy (T6-temper condition) to copper. J. Mater. Process. Technol. 172(1), 110-122 (2006)

8. A. Abdollah-Zadeh, T. Saeid, B. Sazgari, Microstructural and mechanical properties of friction stir welded aluminum/copper lap joints. J. Alloys Compd. 460(1), 535-538 (2008)
9. P. Xue, D.R. Ni, D. Wang, B.L. Xiao, Z.Y. Ma, Effect of friction stir welding parameters on the microstructure and mechanical properties of the dissimilar Al-Cu joints. Mater. Sci. Eng. A 528(13), 4683-4689 (2011)

10. D. Zuo, S. Hu, J. Shen, Z. Xue, Intermediate layer characterization and fracture behavior of laser-welded copper/aluminum metal joints. Mater. Des. 58, 357-362 (2014)

11. D. Zuo, S. Hu, J. Shen, Z. Xue, Intermediate layer characterization and fracture behavior of laser-welded copper/aluminum metal joints. Mater. Des. 58, 357-362 (2014)

12. S. Chen, Z. Zhai, J. Huang, X. Zhao, J. Xiong, Interface microstructure and fracture behavior of single/dual-beam laser welded steel-Al dissimilar joint produced with copper interlayer. Int. J. Adv. Manuf. Technol. 82(1-4), 631-643 (2016)

13. P. Schmalen, P. Peter, Process robustness of laser braze-welded AlCu connectors. SAE Int. J. Altern. Powertrains 5, 195-204 (2016)

14. T. Berglund, Handbuch der metallographischen Schleif- Polierund Ätzverfahren (Julius Springer Verlag, Düsseldorf, 1940)

15. P. Walker, W.H. Tarn, Handbook of Metal Etchants (CRC Press, London, 1991)

16. G. Petzow, Metallographic Etching (American Society for Metals, Ohio, 1976)

17. G.F.V. Voort, Metallography Principles and Practice (ASM International, Ohio, 1999)

18. I.I.u.H.M. Niederrhein, Chromverbindungen in Anhang XIV der REACH-Verordnung aufgenommen, https://www.ihk-krefe ld.de/de/innovation/arbeits-und-gesundheitsschutz/reach/chrom verbindungen-in-anhang-xiv-der-reach-verordnung-aufgenomme n.html. Accessed 15 Feb 2017

19. G. Vander Voort, E.P. Manilova, Metallographic Etching of Aluminum and Its Alloys, Buehler Ltd, EUA; 2009

20. D.V. 1739, Ätzungen für die makro- und mikroskopische Untersuchungen, CEN; 1996

21. P. Technologies, Metallographic Aluminum Etchants, PACE Technologies ${ }^{\circledR}$ - 3601 E. 34th St. - Tucson, AZ 85713 USA, http:// www.metallographic.com/Etchants/Aluminum\%20etchants.htm. Accessed 15 Feb 2017

22. M. Mohammadtaheri, A new metallographic technique for revealing grain boundaries. Metallogr. Microstruct. Anal. 1, 224-226 (2012)

23. R. Slepian, J. Prohaska, An improved etchants for copper and copper alloys. Metallography 9, 51-61 (1976)

24. G.F.V. Voort, Color metallography. ASM Handb. 9, 493-512 (2004)

25. M. GmbH, Aluminum etching with Photoresists, michrochemicals.eu, http://www.microchemicals.eu/technical_information/ aluminium_etching.pdf. Accessed 12 Feb 2015

26. P. Schmalen, P. Plapper, I. Peral, I. Titov, O. Vallcorba, J. Rius, Composition and phases in laser welded $\mathrm{Al}-\mathrm{Cu}$ joints by synchrotron X-ray microdiffraction. Procedia CIRP 7, 27-32 (2018) 